\title{
The Institutional and Community Capacity for Aboriginal Education: A Case Study
}

\author{
Frank Deer
}

\author{
University of Manitoba
}

\begin{abstract}
O’owe zagakibii'igewin da-ozhibii'igaade bezhig noomaya'ii gii-maajichigaade Anishinaabewi dago mooniyaawi-gikina'amaagewin omaa Kaanada akiing. Ogikina'amaageg gaa-wiiji'iwewaad omaa izhichigewining gii-anishinaabewiwag, giiwaabishkiiwewag gaye. Gichi-anishinaabeg gaye ningoding gii-aabadiziwag. Aaniin jiizhi-minosegiban, awe gaa-niigaanishkang ogii-gaganoonaa' bebakaan awiya' gaagikina'amaageng zhigwa gii-ayizhaa bekish wii-zagakibii'iged. Iwe zagakibii'igewin izhisin, eniwek gii-gwaawaanjichigewag gegoo dazhiikigaadeg, wiiji'iweg ayaawaad dago awiyag gechiwaag imaa eyaawaad. Endasing ono gwaawaanjichigewinan, gegoo zenagakin zhigwa gegoon ge-wiiji’iwesegin, gikenjigaade zhigwa aaniin ezhi-gichiinendaagwak Anishinaabewi-gikina'amaagewin aaniin gaye ezhi-zanagak oodenaang jidazhi-gikina'amaageng.

This study explored the institutional and community capacity for Aboriginal education in one urban school district in Canada that recently established a formal Aboriginal education programme. Participants in this study were Aboriginal and non-Aboriginal education professionals, as well as Aboriginal Elders directly and indirectly affiliated with the study school district. Using a qualitative approach, I conducted interviews with participants and observed in-school activities in an effort to acquire data. I found that the physical, political, human resource, and community capacities were, in varying degrees, sufficiently developed to provide Aboriginal education programming. Within each of these capacities, challenges and perceived opportunities have led to an acknowledgement of the importance of Aboriginal education as well as an appreciation of the difficulties of offering such programming in an urban educational environment.
\end{abstract}

Keywords: Indigenous education; institutional capacity; community capacity 


\section{The Institutional and Community Capacity for Aboriginal Education: A Case Study}

Education has become an important issue for Aboriginal Canadians and federal, provincial, and municipal governments in Canada (Gray, 2011). For many Aboriginal Canadians in urban areas this may be particularly true (Hanson, 2005). Development of relevant education programming that emphasizes the unique manifestations of Aboriginal knowledge, heritage, consciousness, and tradition may be an important step toward positive social change for Aboriginal peoples (Bastien, 2012).

Recently published population data indicate that the Aboriginal peoples in Canada are growing faster than any other group (Statistics Canada, 2009). In terms of growth, Canada's Aboriginal population has increased 45\% since 1996-compared to approximately $8 \%$ for non-Aboriginal populations. Concerning educational success, Aboriginal peoples in Canada have not experienced the same success as their nonAboriginal counterparts; 64\% of First Nations men aged 25 to 54 living on a First Nation reserve have not completed high school. Although those who live off reserve (41\%) have experienced slightly better success, both groups lag behind their non-Aboriginal counterparts (18\%). There are similar gaps between Aboriginal and non-Aboriginal peoples in the area of post-secondary education - in one Canadian province, only $8 \%$ of Aboriginal peoples have a university degree, compared to $22 \%$ of non-Aboriginals. A strong correlation exists between a lack of secondary or university credentials and employability amongst Aboriginals in Canada-indeed, 70\% of Aboriginal peoples residing in the City of Winnipeg were employed in 2006 compared to 85\% of nonAboriginals (Auditor General of Canada, 2004).

With Canada's secondary schools being home to growing populations of Aboriginal students who are experiencing significant problems in regard to school attendance and graduation (Carr-Stewart, 2006), the relevance of Aboriginal education, both in its cultural and practical manifestations, merits examination. At a time when the movement for improved academic success and increased participation in the labour market amongst Canada’s Aboriginal peoples has progressed (Lutz, 2008), development of culturally and practically relevant educational programming (i.e., curriculum and pedagogy) that is responsive to the needs of Canadian Aboriginal peoples is especially appropriate.

Many in education today advance the notion that an essential relationship exists between students' culture and the way in which they acquire knowledge, manage and articulate information, and synthesize ideas (Cajete, 1999). What this notion suggests is that schools should be environments where teachers engage their students in a way that allows them to explore and affirm aspects of their own identity while facilitating academic success (CampbellJones, CampbellJones, \& Lindsey, 2010). Since primary and secondary education in Canada approaches teaching with the use of curricular imperatives that give privilege to what is regarded by many as essential curriculum, contemporary scholars and teaching professionals posit that Aboriginal perspectives should be integrated with existing curricular imperatives. The sort of integration called for may involve the use of supplementary resources, curricular material, or knowledge to amend or augment an existing programme of study, which allows classroom teachers to enrich mandatory areas of study with relevant, localized content. The word perspectives 
is the preferred terminology for many teachers who specialize in Aboriginal education because this sort of integration emphasizes the importance of exploring the histories, experiences, values, and knowledge associated with an aspect of Aboriginal culture. In an effort to avoid treating such subject matter in a tokenistic manner-where aspects of Aboriginal culture are explored in a superficial, trivial way that does not explore why such aspects exist and who the people are that they represent-teachers in many jurisdictions are now encouraged to share and explore with their students the respective social contexts associated with a given cultural issue or theme. The exploration of Aboriginal perspectives may provide a more complete picture of Aboriginal culture and the peoples and histories that these perspectives represent.

The recognition of Aboriginal perspectives as an important aspect of public education may be looked upon as a reasonable progression from socio-political events of the last four decades (St. Denis, 2011); the Royal Commission on Aboriginal Peoples is an example of how government has recognized that Aboriginal peoples, their experiences and their cultures, should affect social change (Cook \& Lindau, 2000). Developments such as this recognition have been cited as the reason why some educational jurisdictions have developed resources to assist in the integration of Aboriginal perspectives into mainstream curricula (Deer, 2013). Although Aboriginal education may be frequently perceived as a prospective or constituent part of the post-colonial, anti-racist, and decolonization discourses of educational foundations programmes, the importance of curriculum and teaching issues in Aboriginal education is becoming more prevalent. The focus on curriculum and learning may be regarded as a response to a concern for the lack of authentic Aboriginal education in contemporary schools (Malott, Waukau, \& Waukau, 2009).

\section{The Study}

The purpose of the study was to investigate the institutional and community capacity for Aboriginal education programming in one urban school district in Western Canada that has a recently established Aboriginal education programme, yet has no formal Aboriginal education programming. In attempting to explore contemporary Aboriginal education as an emergent field of practice in public school divisions, I deliberately selected the institutional and communal contexts; concerning the institutional context, the establishment of an Aboriginal education grant for this school division by its respective provincial government represents the first bona fide attempt by the studied school division to institutionalize Aboriginal education that prioritizes the discipline. Regarding the communal context of this study, the presence of a large number of Aboriginal families in this school division's catchment area, many recently arriving to the area from First Nations, has provided opportunities for community-school discussions where language and culture have been an important topic. Most of the Aboriginal families associated with this school division's area do not have members who speak their respective languages (School Division Administrator, January 2013).

Although some of the Aboriginal students of the school involved in this study are of Cree and Métis heritage, most of the families in the study (69\%) are of Anishinaabe descent (School Division Administrator, personal communication, February 2013). In the school where this study took place, Aboriginal students (those whose families declared 
that identity through division registration forms) represented $36 \%$ of the student population.

Using a qualitative approach, I conducted interviews with 12 educators, made class observations, and engaged in participatory research with select learning activities over the course of 6 months. Data collection focused on educators who were affiliated with the division's Aboriginal education programme and the learning activities that were affiliated with this programme; the vast majority of these learning activities took place within the context of one of the centralized programmes where students leave their respective schools to visit the division's resource centre. The general questions associated with the study were:

1. What initiatives/programmes have emerged from a school division with a recently established Aboriginal education programme?

2. What institutional resources have facilitated the delivery of these programmes?

3. What communal resources have facilitated the delivery of these programmes?

The interviews were developed and conducted with the principles of appreciative inquiry in mind. These principles were employed by negotiating "initial intentional empathy" (Elliot, 1999, p. 12) with the participants, an attempt to establish an environment of individual and social affirmation (Cooperrider \& Whitney, 1999). Bogdan's and Biklen's (2007) Participant/Observer Continuum informed the observational research. Because all participants who were of Indigenous background, I employed Wilson's (2008) relationality and relational accountability to ensure that the research was commensurate with currently accepted and appropriate procedures when researching Indigenous peoples (Wilson, 2008). Following data acquisition, data from the interviews were coded to identify themes.

\section{Findings}

Data collection took place in several locations throughout this school division. Although site visits were made to a number of schools within the division, most of the data collection took place in a single divisional resource centre where educational resources and a significant number of staff affiliated with the school division's recently established Aboriginal education programme were situated. The following presentation on findings will be organized within four identified themes that represent the dimensions of institutional capacity that were relevant to this school division: physical capacity, political capacity, human resource capacity, and community capacity.

\section{Physical Capacity}

The establishment of an Aboriginal education programme within this school division was facilitated by the acquisition of significant funding from the respective provincial authority as part of a provincial initiative to enhance the provision of Aboriginal education programming across the province. In planning for a new Aboriginal education programme, this school division established two distinct sub-programmes within the new Aboriginal education programme: a school-based programme within divisional high schools that provides Aboriginal education programming within existing 
curricular imperatives, and a centralized programme for early- and middle-years students who engage in learning opportunities at the division's Aboriginal education centre. Each of these programmes has teaching and non-teaching staff. Teaching and non-teaching staff within the in-school high school programme report to the school principal; although such accountability is officially the case for the teachers and non-teaching staff at the centralized Aboriginal education centre- a centre that is housed in an educational support building for a variety of different programmes such as EAL and industrial arts-the centralized Aboriginal education centre is where the division's coordinator for Aboriginal education operates and has unofficial administrative responsibility for Aboriginal Education. The coordinator, whose role is to oversee the Aboriginal education programme, which includes programme delivery as well as the initiation of new/necessary curricular programming, is the instructional leader of the division's Aboriginal education programme.

Three high school Aboriginal education programmes, each staffed by one teacher for whom the high school principals have principal supervisory responsibility, exist within the division's Aboriginal education programme. These programmes are intended to support students of Aboriginal background to achieve academic success through focused and, at times, culturally relevant education. Although there are some curricular and non-curricular (i.e., activities in the school but not apropos of in-class curricular programming) opportunities for students to explore Aboriginal issues outside the context of the Aboriginal education programme, a large amount of educational programming that utilizes Aboriginal content are within the context of the in-school Aboriginal programming. As one teacher noted:

The [in-school programme] has lots of Aboriginal materials and topics. They also have a lot of visual material like posters. These are put up by the [in-school programme] teacher and are in the class or out in the hall sometimes. They're the only ones who do stuff like that. Other classes cover Louis Riel and a few other topics, but not nearly as much as [the in-school Aboriginal education programme]. (personal communication, February 2013)

Although there is nothing ethno-culturally remarkable about the classroom space that is utilized in any of the in-school programmes, the respective teachers for these programmes have ventured to affect the classroom climates through Aboriginal artefact and print media use. These materials, which have been intended to support curricular goals within the schools, allow some reference support for students' learning experiences. In addition to these spaces, students have had opportunities to explore aspects of the Canadian Aboriginal experience outside of the school for the purposes of curricular learning, socializing, and participation in Indigenous ceremonies. Emphasized in the section on human resources, the participation of Aboriginal Elders has led to opportunities for engagement with different physical spaces for a variety of different purposes such as interaction for learning in a smudge room.

The centralized Aboriginal education programme for early- and middle-years students is the larger of the two sub-programmes and has served 40 schools and approximately 4000 students in its first year of programming. The centralized Aboriginal education programme, which is staffed by five teacher[s] and two support staff, provides 
learning opportunities for the emergent and existing Aboriginal education areas. Topics such as treaty education, environmental education, quasi-spiritual character education (e.g., the seven grandfather teachings), geographical and historical issues, and arts and sciences are explored in this programme. The physical space of the centralized centre accommodates a library of Aboriginal materials, a collection of Aboriginal artefacts, a collection of curricula and teaching resources, and a number of learning spaces that incorporate a circular motif. This motif is commensurate with those embedded in Indigenous cultures and traditions. As one teacher noted:

We've tried to incorporate the medicine wheel and circular themes into what we do. Sometimes it helps get kids talking. Maybe it's because it's a change from the regular classroom, but it seems to help. We try to learn, but we also try to get to know one another. If we in the circle, then we sort of equal. (personal communication, January 2013)

One aspect of the physical spaces provided by the centralized portion of the division's Aboriginal education programme is a smudge room - a spiritually significant space where individuals may participate in a smudge. The smudge, a ceremony of "purification of the mind, body and spirit" (MFNERC, 2008, p.9) that involves the burning of any or all of the four sacred medicines, is a development that has been seen in educational jurisdictions other than the one investigated and is viewed as an essential dimension of Aboriginal cultural practice (Audlin, 2005). Similar to the need for smudging spaces is the need for authentic experiences with Aboriginal content through the leadership of Aboriginal Elders. As is the case with the in-schools programme described earlier, Elder participation in learning experiences has not only enhanced inclass learning through enriched exploration of Indigenous knowledge, but also it has taken the learning experience outside the classroom for learning, ceremonial, and contextual reasons.

This school division benefits from a measure of diversity in the sorts of physical space provided to their recently established Aboriginal education programme. In response to early, middle, and senior years students as well as the field of Aboriginal education as a developing priority, the two models of programme delivery that utilize several locations in the schools and into the community have provided students with not only studentcentred learning opportunities but also with culture-centred learning that places learning within appropriate contexts.

\section{Political Capacity}

During the course of this study, some reference was made to the current sociopolitical climate of Canada in relation to Aboriginal peoples. Through their teacher education programmes, their professional development programmes, and/or their respective professional learning communities, teachers and non-teaching professionals have had opportunities to engage with others in an effort to acquire knowledge of Aboriginal peoples, history, and issues in Canada. An important element to these discussions was the educational dimension of the Canadian Aboriginal experience that explored the notion of how such content can be incorporated into a student's learning experiences. As one teacher stated: 
There is a notion that Aboriginal perspectives should be integrated into school activities. What is difficult is the issue of teaching. What should we cover? How do you cover it? I didn't learn this when I was in school. Now there's lots of content, so when so much of it is about experiences, how do you replicate those experiences? (personal communication, March 2013)

Another teacher noted that:

This programme does a lot of teacher professional learning - which really affects kids. If you decrease teacher apprehension of Aboriginal perspectives and increase their knowledge, that will be a benefit to the students. So this programme is especially preoccupied with professional development. (personal communication, February 2013)

These references by participants were significant when compared to some of the recent policy developments that took place in this school division shortly before the establishment of their Aboriginal education programme. The participant's comments on this issue were rather commensurate with new divisional policy and were evidence that this divisional policy had a sort of political immediacy. The divisional policy, enacted in 2008 and intended to facilitated bona fide programming development, reflects contemporary Canadian socio-political views on Aboriginal peoples in a post-RCAP era, affirms constitutional and tacitly-held understandings on Aboriginal peoples:

It is the [School Division's] view that, in Canadian society where progress is facilitated to embrace diversity, ethical governance promotes appreciation, by all of our students, for the unique ethno-cultural identities of Canadian Aboriginals and their important contributions to our communities (Amended for purposes of maintaining confidentiality). (Division policy, 2008)

The political dimension of institutional capacity was also reflected in this study in the sort of academic programming already engaged in by students, particularly high school students, through their respective social studies classes. Topics such as social justice, Canadian history, and citizenship have provided students with opportunities to engage critically with themselves and the social and political climates of Canada, thus allowing the imperatives for social betterment espoused through such things as the Prime Minister's apology in 2008 to be discussed in tandem with other issues. Explorations of residential schools, the sixties scoop, Aboriginal role models, and stories of success were witnessed in numerous high school classes in this study.

\section{Human Resource Capacity}

Aboriginal education, as a field of study and practice, is a relatively new discipline in Canada. Because of this, a palpable lag exists between the development of this field in a progressive educational climate and the development of an education workforce that can support the development of curricula, professional development, teacher education, and other human resource areas essential to academic success in the area of Aboriginal education. In Canada, the movement for contemporary Aboriginal education programmes has its roots, to a large extent, in the Royal Commission on Aboriginal Peoples, which released its final report in 1996 (Indian and Northern Affairs 
Canada, 1996). Although the recommendations of the report were not significantly implemented at a federal level, a number of initiatives emerged during the socio-political progress that was experienced in the years following the report (Dickason, 2002). In many educational jurisdictions in Canada, this era of progress saw the development of new school curricula, the appropriate amendment of existing school curricula, and the establishment of Aboriginal education as a bona fide dimension of teacher education (to name a few). The school division in this study has seen some developments in the area of Aboriginal education that are commensurate with the era of change in a post-RCAP society. The human resources dimension as seen in this study will be presented by exploring the roles of teachers, non-teaching professionals, and community members who have responsibilities within the school in curricular and non-curricular contexts.

Teachers in this school division are at different stages of their respective careers. However, most of teachers affiliated with the division's Aboriginal education programme are in the early stages of their teaching careers - only one teacher affiliated with the programme has been teaching for more than ten years; the others are in the first three years of their careers. This indicates that the new teachers in this Aboriginal education programme, all of whom received their respective teaching degrees and certification in the province in which they now work, have academic backgrounds that included mandatory Aboriginal education. In the province in question, the mandatory Aboriginal education course for all teacher education students has been in existence for five years. This course was an opportunity for students to explore the historical, curricular, and pedagogical dimensions of Aboriginal education. Commensurate with the initiatives that led to the mandatory teacher education courses are professional development opportunities and expectations for focus on Aboriginal student success and Aboriginal content. As one teacher stated:

For teachers who are non-Aboriginal or who are but are not in touch with their ancestry or with Aboriginal issues, it's important to keep learning. Some content is easy to retain, but because there are so many facets for native people like history, ceremony, stories, and artistic things, ongoing professional development is important. (personal communication, February 2013)

Programmes such as the one investigated in this study have ventured to staff their respective programmes with teachers of Aboriginal identity. Like other labour sectors, there are mandates developed by this school division to provide opportunities for Aboriginal professionals an opportunity through stated preference for Aboriginal candidates or through the creation of professional positions that would benefit from the community-based knowledge of Aboriginal cultures and languages. Through discussion with the participants of this study, there appears to be a tacit understanding amongst staff in this school division that programmes that target Aboriginal content and/or focus upon Aboriginal student success may be well served by non-Aboriginal teaching and support staff, but are best served by Aboriginal staff. As one participant stated:

Having Aboriginal teachers has the potential to facilitate authentic learning experiences. If teachers share a cultural background with Aboriginal families, then it's possible that there can be quicker, stronger connections. Respect is an important thing with many of our Aboriginal families and there is a respect for 
teachers who have similar experiences to that of their own. (personal communication, March 2013)

An important component of the two modes of delivery of Aboriginal education in this school division is the work of non-teaching professionals. Sometime referred to as educational/teaching assistants, these individuals are sometimes responsible for facilitating learning for a large number of students, and at times, for assisting specific students who may have difficulties learning. Within this school division's Aboriginal education programme, non-teaching assistants work in both the in-school high school programmes and in the centralized programme. However, non-teaching assistants in the in-school high school programme are appointed and supervised by the respective school administrative team (principals and vice principals); these non-teaching assistants' principal focus is on academic support and classroom management. However, nonteaching assistants in the centralized programme, who are referred to here as community support workers, are hired by the instructional support centre and supervised by the coordinator of the Aboriginal education programme. Although it can be said that, like their in-school counterparts, the non-teaching assistants of the centralized programme are focused on academic support, yet the tasks performed by these non-teaching assistants are markedly different and represent perhaps the most valued human resource of the entire Aboriginal education programme: the infusion of unique manifestations of Aboriginal knowledge, heritage, consciousness, and tradition into the learning experiences of students. For instance, these non-teaching assistants, who happen to be of Aboriginal identity, are frequently responsible for the acquisition and production of artefacts that support Aboriginal content, performance/leadership of Aboriginal ceremonial and quasiceremonial activities, and the consultative support for uninitiated colleagues when information on Aboriginal knowledge, heritage, consciousness, and tradition is required (a frequent situation in this Aboriginal education programme).

An interesting observation during the course of this study was the sort of leadership roles that the Aboriginal non-teaching assistants in the centralized programme bore within the broad activities of this school division's Aboriginal education programme. Although there are differences in professional rank, public regard, and remuneration between the non-teaching assistants and classroom teachers in the programme, this study showed that the need for their services in the successful delivery of Aboriginal content was high. As one teacher stated:

Our community support workers provide outreach services to our communities and specialized cultural integration within classrooms. They provide specialized cultural support and knowledge to our activities by bringing Aboriginal content to classrooms throughout the division. Although others support the curricular part of our programming, our community support workers support specific cultural knowledge. They also provide important family support to our communities. So effectively, they're teaching. (personal communication, February 2013)

As Aboriginal education programming has become more prominent and refined in Canada, many teachers, schools, and school districts have enlisted the assistance of Aboriginal Elders from the community in order to infuse a measure of authenticity that may not otherwise be present in a learning activity or extra-curricular activity. There are 
instances when the sort of Aboriginal knowledge is not accessible for available classroom teachers or other staff and may require specific community perspectives that can only be suitably explored through the guidance of an Elder. During the course of this study, a number of ceremonies, celebrations, and events took place where Aboriginal perspectives were relevant and/or incorporated and that required the leadership of an Aboriginal Elder. Similar situations of a curricular nature also saw the participation of Aboriginal Elders to provide leadership and/or guidance in such activities as the exploration of the residential schools experience. During the school year in which this study took place, the school division that was investigated was occasioned by the assistance of one Elder in particular whose quasi-formal appointment (i.e., although not a full-time employee, this Elder was asked to support different schools on a regular basis) has led to an important presence in the division that has further led to a productive relationship amongst schools in the division from which students benefitted.

\section{Community Capacity}

As the field of Aboriginal education has grown in Canada over the past two decades, the recognition and affirmation of community involvement as an essential dimension of potential and existing programming has become more prevalent. The term community in this context is in reference to the Aboriginal communities that are most closely affiliated with the school in which Aboriginal educational programming is being provided. For many in this study, the reason for community involvement is to enable schools to provide authentic programming that speaks to the unique manifestations of Aboriginal knowledge, heritage, consciousness, and tradition. As one participant stated:

We have an Elder who helps us with cultural ceremonies, blessings, and traditions. For example, this Elder has used music, theatre, and stories to explore sacred teachings with our students. He does things like this with each of our [in-school high school programme] schools and with many other high schools. He speaks his Indigenous language as well, which is a great benefit. (personal communication, February 2013)

Commensurate with what is understood with the role of Aboriginal Elders in schools, the necessity of utilizing and/or incorporating Aboriginal community into Aboriginal educational programming is to ensure that Aboriginal content has relevance to the students of a particular school. In an effort to ensure the Canadian Aboriginal experience is not presented in a generalized way but a way that recognizes the notion that there is a wide ethnic diversity across Canada's Aboriginal peoples and that generalized educational content may cheat the unique dimensions of particular Aboriginal communities. For the school division that was investigated here, there were three principal Aboriginal groups represented: Anishinaabe, Cree, and Métis. Within these groups, numerous Aboriginal communities were represented, including several First Nations, one Métis provincial jurisdiction reflecting a small number of specific communities, as well as three urban Aboriginal groups that are discernible by way of the urban communities that they share. Parental involvement, ancestral language learning opportunities, community events, Aboriginal Elder involvement, and occasional conferral with Aboriginal community members on education programming issues have facilitated the participation of the local Aboriginal communities in a way that provides students with 
an opportunity to understand the local Aboriginal peoples experiences, ways of life and perspectives.

\section{Discussion}

Within each of the institutional capacities mentioned earlier, challenges and perceived opportunities have led to an acknowledgement of the importance of Aboriginal education as well as an appreciation of the challenges of offering such programming in an urban educational environment. Although these issues were discussed in the findings section of this article, the efforts of teachers, non-teaching professionals, and administrators in the school division investigated in this study have led to the emergence of several issues that may be problematic for other school divisions with similar initiatives.

When considering the stated foci of this school division's Aboriginal education programme as well as the perspectives shared by some of the study's participants, it is clear that there are two principal focuses of the programme: the integration of Aboriginal perspectives in school programming and the academic success of Aboriginal students. As stated earlier, two sub-programmes were investigated in this study: an in-school high school programme and a centralized programme for early- and middle-years students. These two sub-programmes represent programme delivery each addressed the two principal focuses in different ways. It may be important to note that the in-school high school programme took the form of specialized classes, with specially appointed teachers-classes that were populated with Aboriginal students. In the centralized programme for early- and middle-years students, classes that visited the centre were not exclusively Aboriginal students but rather classes that consisted of students of a variety of different backgrounds. In fact, it was frequently the case that Aboriginal students in these early- and middle-years classes were the minority.

Are these differences in purpose of the two programmes problematic? In the centralized early- and middle-years programme, the mix of different students in a programme where the content was presented as bona fide curricula appeared to represent the sort of class where content was judged relevant to all students. In the in-school high school programme (one that was available to Aboriginal students only), the delivery of content of an Aboriginal or non-Aboriginal nature to Aboriginal students, intended to support academic success of Aboriginal students, may be perceived ghettoizing the provision of programming to a particular group of students. As academic success for Aboriginal students in this school division is closely associated with attendance and frequently with the family/personal circumstances that lead to truancy or lack of success, the activities of this Aboriginal education programme may be too closely associated with the activities of a student services programme.

The administrative model utilized for this programme, one nominally academic programme for public schools that corresponds to provincial curricula, is one that resembles many other curricula-based public school programmes (e.g., a divisional mathematics programme with a dedicated coordinator): one that has a dedicated programme coordinator that supports initiatives and teaching in a specific content area. Ordinarily, the programme coordinator of such a programme would be responsible for curricular and pedagogical development, initiatives and support within the programme for 
teaching professionals who are supervised by school principals or other designated administrators. Although this model is clearly at work in the school division investigated in this study, some issues of professional jurisdiction may lead to difficulties in the execution of the programme such as the supervision of teachers and other staff as well as the imperatives of student support. 


\section{References}

Auditor General of Canada. (2004). Chapter 5: Indian and Northern Affairs Canada education program and post-secondary student support. Report of the Auditor General. Ottawa, ON: Author.

Audlin, J. D. (2005). Circle of life: Traditional teachings of Native American Elders. Sante Fe, NM: Clear Light Publishing.

Bastien, B. (2012). Indigenous pedagogy: A way out of dependence. In K. Burnett \& G. Read (Eds.), Aboriginal history: A reader (pp. 14-26). Don Mills, ON: Oxford University Press.

Bogdan, R. C., \& Biklen, S. K. (2007). Qualitative research for education: An introduction to theories and methods ( $5^{\text {th }}$ ed.). Boston, MA: Pearson.

Cajete, G. A. (1999). Igniting the sparkle: An Indigenous science education model. Skyand, NC: Kivaki Press.

CampbellJones, F., CampbellJones, B., \& Lindsey, R. (2010). The cultural proficiency journey: Moving beyond ethical barriers toward profound school change. Thousand Oaks, CA: Corwin.

Carr-Stewart, S. (2006). First Nations education: Financial accountability and educational attainment. Canadian Journal of Education, 29(4), 998-1018.

Cook, C., \& Lindau, J. (2000). Aboriginal rights and self-government. Montreal, PQ: McGill-Queens Press.

Cooperrider, D. L., \& Whitney, D. (1999). Appreciative inquiry. In P. Holman \& T. Devane (Eds.), Collaborating for change (pp. 4-16). San Francisco, CA: BerrettKoehler.

Deer, F. (2013). Integrating Aboriginal perspectives in education: Perceptions of preservice teachers. Canadian Journal of Education, 36(2), 175-211.

Dickason, O. P. (2002). Canada's First Nations: A history of founding peoples from earliest times. Don Mills, ON: Oxford University Press.

Elliot, C. (1999). Locating the energy of Change: An introduction to appreciative inquiry. Winnipeg, MB: International Institute for Sustainable Development.

Gray, L. (2011). First Nations 101: Tons of stuff you need to know about First Nations people. Vancouver, $\mathrm{BC}$ : Adaawx

Hanson, S. (2005). BE adult 10 program history in Saskatoon Public Schools. Saskatoon, SK: Author.

Indian and Northern Affairs Canada. (1996). Report of the Royal Commission on Aboriginal Peoples. Ottawa, ON: Author.

Lutz, J. (2008). Makuk: A new history of Aboriginal-White relations. Vancouver: UBC Press. 
Malott, C. S., Waukau, L., \& Waukau-Villagomez, L. (2009). Teaching Native America across the curriculum: A critical inquiry. New York: Peter Lang.

Manitoba First Nations Education Resource Centre (MFNERC).(2008). First Nations teachings and practices. Winnipeg, MB: Author.

St. Denis, V. (2011). Silencing Aboriginal curricular content and perspectives through multiculturalism: “There are other children here.” Review of Education, Pedagogy, and Cultural Studies, 33(4), 306-317.

Statistics Canada. (2009). Aboriginal data at Statistics Canada. Ottawa, ON: Author.

Wilson, S. (2008). Research is ceremony: Indigenous research methods. Black Point, NS: Fernwood. 